\title{
Is Engineering Education Research Global? The Answer May Surprise You.
}

\section{Bill Williams, ESTBarreiro, Setubal Polytechnic Institute}

Bill Williams originally trained as a chemist at the National University of Ireland and went on to work in education in Ireland, UK, Eritrea, Kenya, Mozambique and Portugal. He lectures on technical communication at the Instituto Politécnico de Setúbal and at IST, Universidade de Lisboa.

\section{Dr. Phillip C. Wankat, Purdue University, West Lafayette}

Phil Wankat received a BSChE from Purdue University, an MS and $\mathrm{PhD}$ in chemical engineering from Princeton University and an MSEd from Purdue. He is a distinguished professor at Purdue with a joint appointment in Chemical Engineering and Engineering Education.

Pedro Neto P.E., Polytechnic Institute of Setubal

Mr. Carlos Alexandre Tiago, ESTBarreiro, IPS

Research Assistant on Wedo, ESTBarreiro, Setúbal Polytechnic Institute. 


\title{
Is Engineering Education Research Global? The Answer May Surprise You.
}

\author{
Bill Williams $^{1,2}$, Phillip Wankat ${ }^{3}$, Pedro Neto $^{1}$, Carlos Tiago ${ }^{1}$ \\ ${ }^{1}$ ESTBarreiro, Instituto Politécnico de Setúbal, ${ }^{2}$ CEG-IST, Universidade de Lisboa, \\ ${ }^{3}$ Purdue University
}

ASEE Annual Conference, Indianapolis, June 15-18, 2014

\section{Introduction}

There has been an increasing focus on the globalization of Engineering Education Research (EER) in recent years and recognising this, in 2007 the editors of the Journal of Engineering Education (JEE) and the European Journal of Engineering Education (EJEE), Jack Lohmann and Jean Michel, respectively, launched a worldwide initiative called Advancing the Global Capacity for Engineering Education Research. In a resulting paper published jointly by EJEE and JEE in 2010 (Jesiek, Borrego \& Beddoes, 2010), it was suggested that "the field of engineering education research is going global" and Jesiek and colleagues went on to propose a model whereby engineering education scholarship could advance locally and globally via cycles of translation and enrolment which would connect local practice and contexts with a global core of knowledge. These authors encouraged EER practitioners to "look for opportunities to translate research questions, theories, methods, and findings so they are readable and relevant across national and institutional boundaries" and urged scholars to "think globally about the development of engineering education as a research field, while acting locally to enrol new actors and perform context-sensitive translations".

In a similar vein, Alan Cheville, in a talk posted on IEEE TV, stresses the importance of research into global competencies to assist engineering educators "to make our students into better global citizens" (Cheville, 2012).

However, an analysis of empirical research in leading EER journals up to 2008 (Jesiek et al., 2011) showed that the majority of published authors in the analysed articles came from the US (36\%) with the EU and Australia providing $29 \%$ and $23 \%$ respectively and the level of international co-authorship was relatively low at $8 \%$. Although we might assume that in the intervening years this trend might have diminished due to increased globalization, we note that a recently published list of the most collaborative co-authors in EER (Strobel et al 2012) contains only US scholars. Furthermore, a recent analysis of 24,172 papers in engineering education research journals and conference proceedings over the period 2000-2011 (Xian and Madhavan, 2014) has found that in-state collaboration within the US is significantly more frequent than between-state collaboration which suggests that geographical location can strongly influence how scholars form collaborations.

The three empirical studies above focused on the most published authors and those with whom they coauthored but do not provide information on what sources these scholars consulted when carrying out 
their work. Even if published research in the principal journals and conferences in the field does come predominantly from US authors, these researchers may nevertheless be becoming more global in their outlook and be considering global sources in their research. One credible way of detecting such a trend is to analyse the sources cited by authors and that is one of the approaches adopted here. This perspective is in line with a 2011 position paper by Borrego and Bernhard who suggest that "EER has emerged as an internationally connected field of inquiry" and go on to describe the U.S. and Northern and Central European approaches to EER as "two examples of the diversity of approaches"( Borrego and Bernhard, 2011). These authors set out six criteria for quality scholarship in engineering education in an international context. We selected the second of these criteria, that quality scholarship should be "informed by theory and other literature describing prior work within and beyond the field/home country" as an indicator which should be susceptible to empirical measurement by studying citation patterns of publications of leading journals in the field. We note that when such an analysis was carried out for articles in JEE from 1993 to 2002 (Wankat, 2004) the list of 33 of the most highly cited source authors contained 32 US-based scholars and 1 from Canada.

\section{Methodology and Procedure}

To what extent has EER become global? To test such a claim we hypothesized that author and citation data from US and European journals would demonstrate globalization. In other words, the affiliations of the authors in the journals would show a global rather than local spread (taking Europe as a whole for the study) and also that the pool of sources the authors cite would be global.

Given that $J E E$ and $E J E E$ are highly cited journals published respectively by the American and European Societies for Engineering Education and that they participated jointly in the 2007 Advancing the Global Capacity for Engineering Education Research initiative, the authors chose JEE as a representative of US and EJEE of European EER journals. Author affiliations were collected for all authors from the 2010 through 2013 issues. In addition, a list of frequently cited sources was developed, and the country of professional affiliation for each source was determined. We initially started with the list of 33 frequently cited sources in JEE published in 2004 (Wankat, 2004) and added source names from the October 2013 list of the most highly-cited EJEE papers (maintained on the publisher's website). Then we added to this list other frequently cited authors found when manually analysing the reference list of each journal articles. The sources were separated into three groups based on geographic location: US, Europe, and Other (all other countries). Citations were counted from regular papers (excluding editorials, guest editorials, and book reviews) and self-citations were not included. The cited authors in each journal were ranked according to the number of times they were cited. Wankat's 2004 study listed the 33 most frequently cited sources and we have taken a similar approach in this paper and compiled the sources in JEE cited 17 or more times while for EJEE we took 8 or more citations as the cut-off point. This produces lists of 34 and 35 respectively as shown in Tables 1 and 2 below.

\section{Results}


There were $109 \mathrm{JEE}$ articles with a total of 395 authors over the 4 years in question while EJEE published 204 articles with 529 authors. The distribution of the affiliations of these authors is shown in Figure 1.
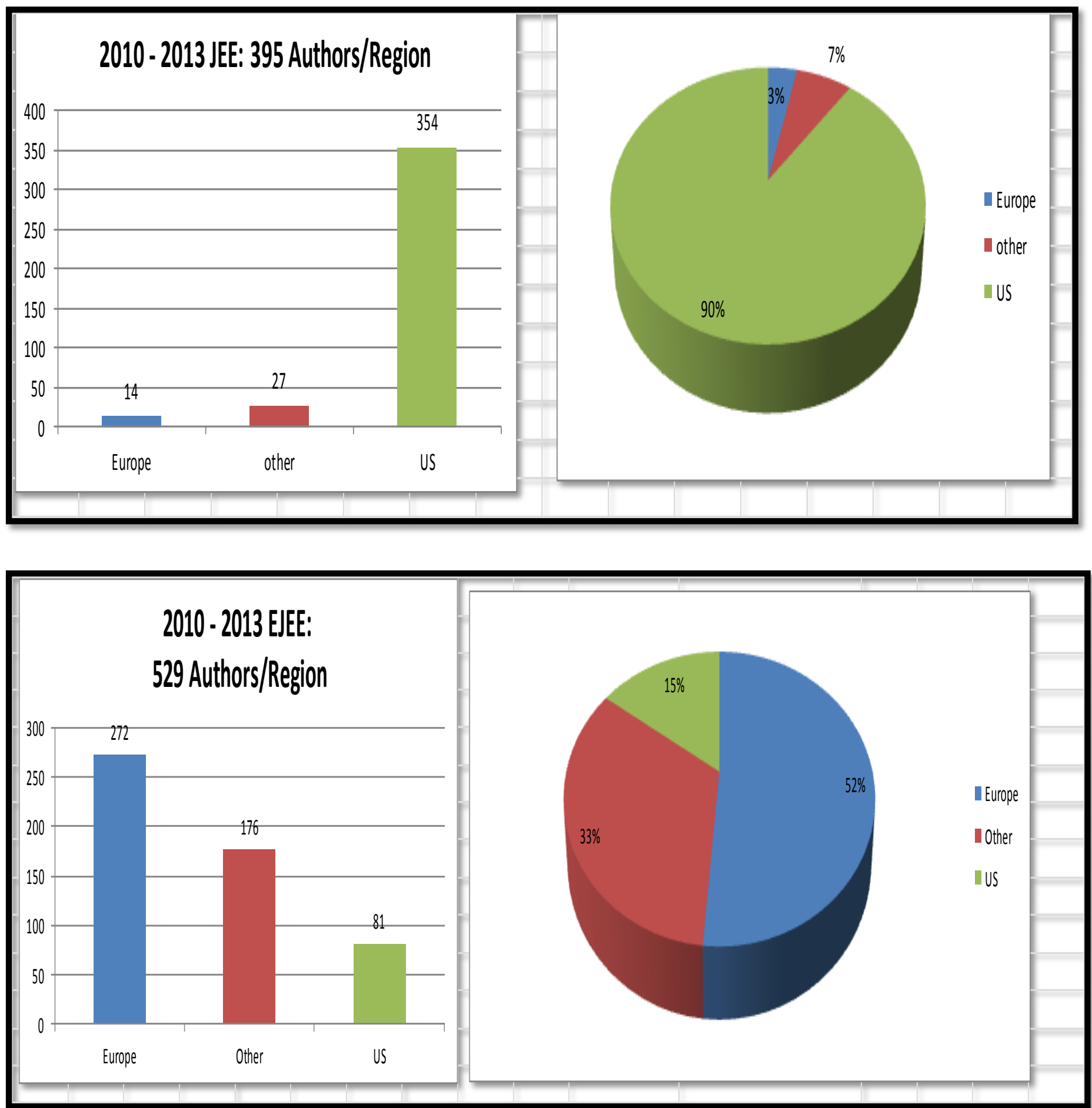
Figure 1: Affiliation distribution of authors in JEE and EJEE articles (2010 - 2013)

\begin{tabular}{|c|c|c|c|}
\hline Rank & Author & Region & Citations \\
\hline 1 & Felder, R M & US & 55 \\
\hline 2 & Kolmos, A & Europe & 35 \\
\hline 3 & Johnson, DW \& RT & US & 27 \\
\hline 4 & Smith, K & US & 26 \\
\hline 5 & ABET & US & 22 \\
\hline 6 & Brent, R. & US & 22 \\
\hline 7 & Biggs, J. & Europe & 17 \\
\hline 8 & De Graaff, E & Europe & 16 \\
\hline 9 & Trevelyn, J & Other & 15 \\
\hline 10 & Marton, F & Europe & 14 \\
\hline 11 & Atman, C & US & 13 \\
\hline 12 & Borrego, M & US & 13 \\
\hline 13 & Kolb, D A & US & 13 \\
\hline 14 & NSF & US & 13 \\
\hline 15 & UNESCO & Europe & 12 \\
\hline 16 & Woods, D R & Other & 12 \\
\hline 17 & Miller, $\mathrm{R}$ & US & 12 \\
\hline 18 & Sheppard, S & US & 12 \\
\hline 19 & Baillie, C & Other & 11 \\
\hline 20 & Prince, $\mathrm{MJ}$ & US & 11 \\
\hline 21 & Lindsay, E & Other & 10 \\
\hline 22 & Gardner, A & Other & 10 \\
\hline 23 & Alpay, E & Europe & 9 \\
\hline 24 & Dym, CL & US & 9 \\
\hline 25 & Stice, J & US & 9 \\
\hline 26 & Besterfield-Sacre, M. & US & 9 \\
\hline 27 & Lohmann J & US & 9 \\
\hline 28 & Gill, J & Other & 8 \\
\hline 29 & Willey, K & Other & 8 \\
\hline 30 & ASEE & US & 8 \\
\hline 31 & Eccles, J.S. & US & 8 \\
\hline 32 & Jonassen, D H & US & 8 \\
\hline 33 & Ohland, M & US & 8 \\
\hline 34 & Olds, B & US & 8 \\
\hline
\end{tabular}

Table 1: Highly cited source authors in EJEE (2010 - 2013) 


\begin{tabular}{|c|c|c|c|}
\hline \multicolumn{4}{|c|}{ JEE Sources } \\
\hline Rank & Author & Region & Citations \\
\hline 1 & Felder, RM & US & 63 \\
\hline 2 & NAE & US & 58 \\
\hline 3 & Sheppard, S & US & 57 \\
\hline 4 & Atman, C & US & 48 \\
\hline 5 & Johnson, DW \& RT & US & 43 \\
\hline 6 & Smith, K & US & 40 \\
\hline 7 & Besterfield-Sacre, M. & US & 37 \\
\hline 8 & Bandura, A & US & 36 \\
\hline 9 & Shuman, L & US & 34 \\
\hline 10 & Eccles, J & US & 32 \\
\hline 11 & Olds, B. & US & 32 \\
\hline 12 & Terenzini TP & US & 31 \\
\hline 13 & Latucca, L & US & 31 \\
\hline 14 & Miller, $\mathrm{R}$ & US & 30 \\
\hline 15 & NSF & US & 30 \\
\hline 16 & Brent, R. & US & 29 \\
\hline 17 & Ohland, M. & US & 28 \\
\hline 18 & Seymour, E & US & 28 \\
\hline 19 & Bransford & US & 27 \\
\hline 20 & Adams, $\mathrm{R}$ & US & 25 \\
\hline 21 & NRC & US & 25 \\
\hline 22 & Prince, M.J. & US & 24 \\
\hline 23 & Streveler, R. & US & 24 \\
\hline 24 & Litzinger $\mathrm{T}$ & US & 22 \\
\hline 25 & Newstetter, W & US & 22 \\
\hline 26 & Agogino, $A$ & US & 21 \\
\hline 27 & Borrego, M & US & 21 \\
\hline 28 & Simon, $\mathrm{H}$ & US & 21 \\
\hline 29 & ABET & US & 20 \\
\hline 30 & Astin, A W & US & 20 \\
\hline 31 & Hewitt, $\mathrm{N}$ & US & 20 \\
\hline 32 & Cross, N. & Europe & 19 \\
\hline 33 & Dym, C L & US & 19 \\
\hline 34 & Johri, A & US & 17 \\
\hline 35 & Vygotsky, LS & US & 17 \\
\hline
\end{tabular}

Table 2: Highly cited source authors in JEE (2010 - 2013).

Note: since the Johnson brothers normally publish together, they are treated as a single source. 


\section{Findings}

Whereas affiliations of EJEE authors were fairly evenly distributed around the globe albeit with a preponderance of European researchers over those from the US, Australia, Brazil and South Africa, almost $90 \%$ of JEE authors were from the US. This is in accord with a historical study of the affiliations of authors in JEE and EJEE over 40 years from 1973 to 2013 that showed that while EJEE has traditionally published work by a broadly global set of authors, JEE authors have tended to be almost exclusively North American based (Wankat et al. 2014).

Table 2 shows that citations in JEE are dominated by sources with US affiliations, which does not support our hypothesis. On the other hand, the EJEE data (Table 1) show that while US sources are frequently cited, European and Other authors are also well represented. The short answer to our title question is that in citation terms, European EER is global but US EER not.

The data in Table 2 also reveal a number of other interesting observations. For example, of the 33 top sources on the original JEE list (Wankat, 2004) only 14 occur in the top 33 in Table 2 (Felder, Sheppard, Atman, Johnson \& Johnson, Smith, NSF, Olds, Seymour, Hewitt, Astin, Agogino, ABET, and NRC) sic transit gloria mundi. R. Felder tops both our lists as indeed he did in Wankat's 2004 list of mostcited authors (Wankat 2004). Some US authors such as D. Kolb and M. Borrego are relatively better known in Europe than in the US, and some European authors such as N. Cross are better known in the US than in Europe. Regional differences are clear in some cases - for example, the National Academy of Engineering (NAE) is heavily cited in JEE but only twice in EJEE, and UNESCO is significantly cited in EJEE but was not cited in JEE. On the other hand, ABET was heavily cited in both JEE and EJEE.

One anomaly was observed. If one searches on the EJEE and JEE websites for Benjamin Bloom of taxonomy fame, there are a large number of hits. Despite this, the number of citations of Bloom did not make the cut off for either journal (17 in JEE and 8 in EJEE). Many authors discuss Bloom's Taxonomy without citing it. Apparently the taxonomy has become such a normal part of discourse in EER that many authors believe no citation is needed.

\section{Conclusions}

Whereas the authors published in EJEE and the sources they consult when carrying out their research are drawn globally, this is not the case for scholars published in JEE. If the EER community is to aspire to the kind of quality scholarship characterized by Borrego and Bernhard (2011) there needs to be debate around how such issues can be tackled so as to develop a truly global field of research.

\section{References}

Borrego, M., \& Bernhard, J. (2011) "The emergence of engineering education research as an internationally connected field of inquiry." Journal of Engineering Education, 100, 14 - 47. 
Cheville, A. (2012) IMS 2012 Special Sessions: Globalization of Engineering Education and Research: Opportunities and Challenges, retrieved 1 Jan 2014 from https://ieeetv.ieee.org/conferencehighlights/ims-2012-special-sessions-globalization-of-engineering-education-and-researchopportunities-and-challenges-alan-cheville

Jesiek, B. K., M. Borrego \& K. Beddoes (2010) Advancing Global Capacity for Engineering Education Research (AGCEER): Relating Research to Practice, Policy, and Industry. Journal of Engineering Education, 99, 107-119.

Jesiek, B.K., Borrego, M., Beddoes, K., Hurtado, M., Rajendran, P., \& Sangam, D. (2011). Mapping Global Trends in Engineering Education Research, 2005-2008. International Journal of Engineering Education, 27(1), 77-90.

Strobel J., Radcliffe D. F., Yu J.H., Nawaz S., Luo Y.D. and Choi J.H., (2012) Is the Engineering Education Community Becoming More Interdisciplinary?, Proceedings of the 2012 ASEE Annual Conference

Wankat, P. C. (2004) Analysis of the First Ten Years of the Journal of Engineering Education, Journal of Engineering Education 93, 13-21.

Wankat, P.C. Williams B. and Neto P., (2014) Engineering education research in European Journal of Engineering Education and Journal of Engineering Education: citation and reference discipline analysis, European Journal of Engineering Education 39, 1, 7 - 17.

Xian, H. and Madhavan, K. "Anatomy of scholarly communication in engineering education: A big-data bibliometric analysis". Journal of Engineering Education, 103 (3) (forthcoming July 2014). 